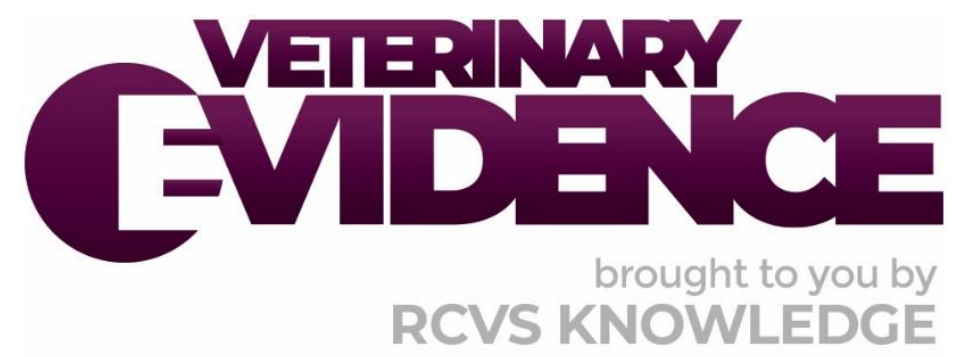

\title{
Efficacy of EMLA ${ }^{\mathrm{TM}}$ cream for reducing pain associated with venepuncture in felines
}

\section{A Knowledge Summary by}

Erina Leask Student ${ }^{1^{*}}$

\footnotetext{
${ }^{1}$ Sydney School of Veterinary Science, The University of Sydney, Head Office JD Steward Building University of Sydney, NSW, 2006, Australia

* Corresponding Author (erina.leask@gmail.com)
}

ISSN: 2396-9776

Published: 15 Jul 2021

in: The Veterinary Evidence journal Vol 6, Issue 3

DOI: https://doi.org/10.18849/ve.v6i3.456

Reviewed by: Myra Forster-van Hijfte (CertVR CertSAM

DipECVIM-cA FRCVS) and Nieky van Veggel (BSC MSc PgC RSci R.AnimSci. CBiol FRSB FHEA)

Next Review Date: 27 Apr 2023 


\section{KNOWLEDGE SUMMARY}

\section{PICO question}

In adult cats undergoing a venepuncture procedure, does the application of a topical lidocaine based anaesthetic to the skin at the venepuncture site reduce the severity of signs associated with pain when compared to no topical anaesthetic?

\section{Clinical bottom line}

\section{Category of research question}

\section{Treatment}

\section{The number and type of study designs reviewed}

Four papers were critically reviewed. Three were prospective, double-blind, randomised, controlled clinical trials, and one was a prospective, double-blind, controlled experimental trial

\section{Strength of evidence}

\section{Moderate}

\section{Outcomes reported}

The application of Eutectic Mixture of Local Anaesthetics $\left(E M L A^{\mathrm{TM}}\right)$ cream to clipped skin over the procedure site, a minimum of 30 minutes prior to the venepuncture procedure, significantly reduced the severity of pain-associated behaviours during jugular phlebotomy in healthy, conscious feline patients when compared to a placebo ${ }^{1,2}$. In felines sedated with dexmedetomidine and either methadone or nalbuphine, the administration of EMLA ${ }^{\mathrm{TM}}$ cream to clipped skin for 20 minutes significantly decreased the severity of pain responses during intravenous (IV) cephalic vein catheterisation when compared to no treatment ${ }^{3}$. In clinically unwell feline patients, the use of EMLA ${ }^{\mathrm{TM}}$ cream on clipped skin at the site of jugular catheterisation 60 minutes prior demonstrated reduced pain responses compared to a placebo, but further investigation with a larger sample size is required to verify statistical significance ${ }^{4}$

\section{Conclusion}

The available evidence moderately supports the hypothesis that EMLA ${ }^{\mathrm{TM}}$ cream is an effective and noninvasive treatment for providing enhanced pain-relief during jugular and cephalic vein phlebotomy for the purposes of blood collection and catheterisation, respectively. The areas for treatment should be clipped free of hair, and the cream applied for a minimum of 30 minutes in non-sedated cats and 20 minutes in cats sedated with dexmedetomidine and either methadone or nalbuphine. Moreover, when applied to normal, intact skin and covered by an occlusive bandage to avoid ingestion, it is well supported by supplementary evidence that EMLA ${ }^{\mathrm{TM}}$ cream has a wide safety margin for topical use in cats $\mathrm{s}^{4,5}$

\section{How to apply this evidence in practice}

The application of evidence into practice should take into account multiple factors, not limited to; individual clinical expertise, patient's circumstances and owners' values, country, location or clinic where you work, the individual case in front of you, the availability of therapies and resources.

Knowledge Summaries are a resource to help reinforce or inform decision making. They do not override the responsibility or judgement of the practitioner to do what is best for the animal in their care. 


\section{Clinical Scenario}

You are a small animal veterinarian working in private practice. In recent years, your clinic has adopted fearfree handling techniques and designated feline-only consultation and treatment rooms in order to reduce iatrogenic stress and provide more positive clinical experiences for feline patients. Recognising that pain is a factor that contributes to the development of fearfulness in veterinary patients, you are concerned that routine procedures such as venepuncture may still be causing undue stress. Therefore, you decide to investigate non-invasive methods for reducing pain associated with venepuncture.

\section{The evidence}

Three prospective, randomised, double-blinded, controlled, clinical trials compared the efficacy of EMLA ${ }^{\mathrm{TM}}$ cream in reducing the severity of pain associated with venepuncture as compared to either a placebo ${ }^{1,4}$ or to no treatment ${ }^{3}$. Two of these studies evaluated the efficacy of EMLA ${ }^{\mathrm{TM}}$ cream in reducing pain associated with jugular venepuncture in conscious feline patients that were either clinically well ${ }^{1}$ or unwell ${ }^{4}$, respectively. The third clinical trial ${ }^{3}$ evaluated the efficacy of $\mathrm{EMLA}^{\mathrm{TM}}$ cream in reducing pain associated with cephalic vein catheterisation in sedated feline patients. A fourth prospective, double-blind, controlled, experimental trial ${ }^{2}$ evaluated the efficacy of EMLA $^{\mathrm{TM}}$ cream in reducing the pain associated with cephalic vein venepuncture using a butterfly infusion set, however, the generalisability of these findings is limited by the lack of randomisation and the fact that these data were collected in an experimental setting ${ }^{8,9}$.

\section{Summary of the evidence}

Crisi et al. (2020) ${ }^{1}$

\section{Population: Recruitment:}

- Feline patients referred to the Veterinary Teaching Hospital (VTH) of the University of Teramo, Italy, between April and July 2019.

- Recruited patients were enrolled if they met eligibility and inclusion criteria following the collection of patient history, complete clinical examination, and behaviour assessment by an appointed operator.

- An adapted version of the Modified Behavioural Pain Scale (MBPS) by Wagner et al. ${ }^{4}$ was used to score the compliance of subjects to handling during initial clinical examination.

- Behaviours measured included magnitudes of struggling and aggression, measured as attempts to swipe or bite.

\section{Criteria for eligibility and inclusion:}

- Healthy.

- Owned, with attainment of informed owner consent.

- Referred to the VTH for the purpose of a health check, blood donation, or a pre-anaesthetic evaluation prior to neutering.

- Compliant to handling during clinical examination (scored $<2$ on the MBPS).

\section{Criteria for exclusion and rejection:}

- Presence of skin irritation, inflammation, or wounds on the neck region prior to venepuncture.

- Non-compliant during initial clinical examination (scored $\geq 2$ on the MBPS). 


\begin{tabular}{|c|c|}
\hline & $\begin{array}{l}\text { Enrolled study population: } \\
\text { - } 18 \text { healthy domestic shorthair cats: } \\
\text { - } 14 \text { males; three entire and } 11 \text { neutered. } \\
\text { - } \quad \text { Four females; one entire and three neutered. } \\
\text { - } \text { Age range between } 1-15 \text { years. }\end{array}$ \\
\hline Sample size: & 18 cats \\
\hline Intervention details: & 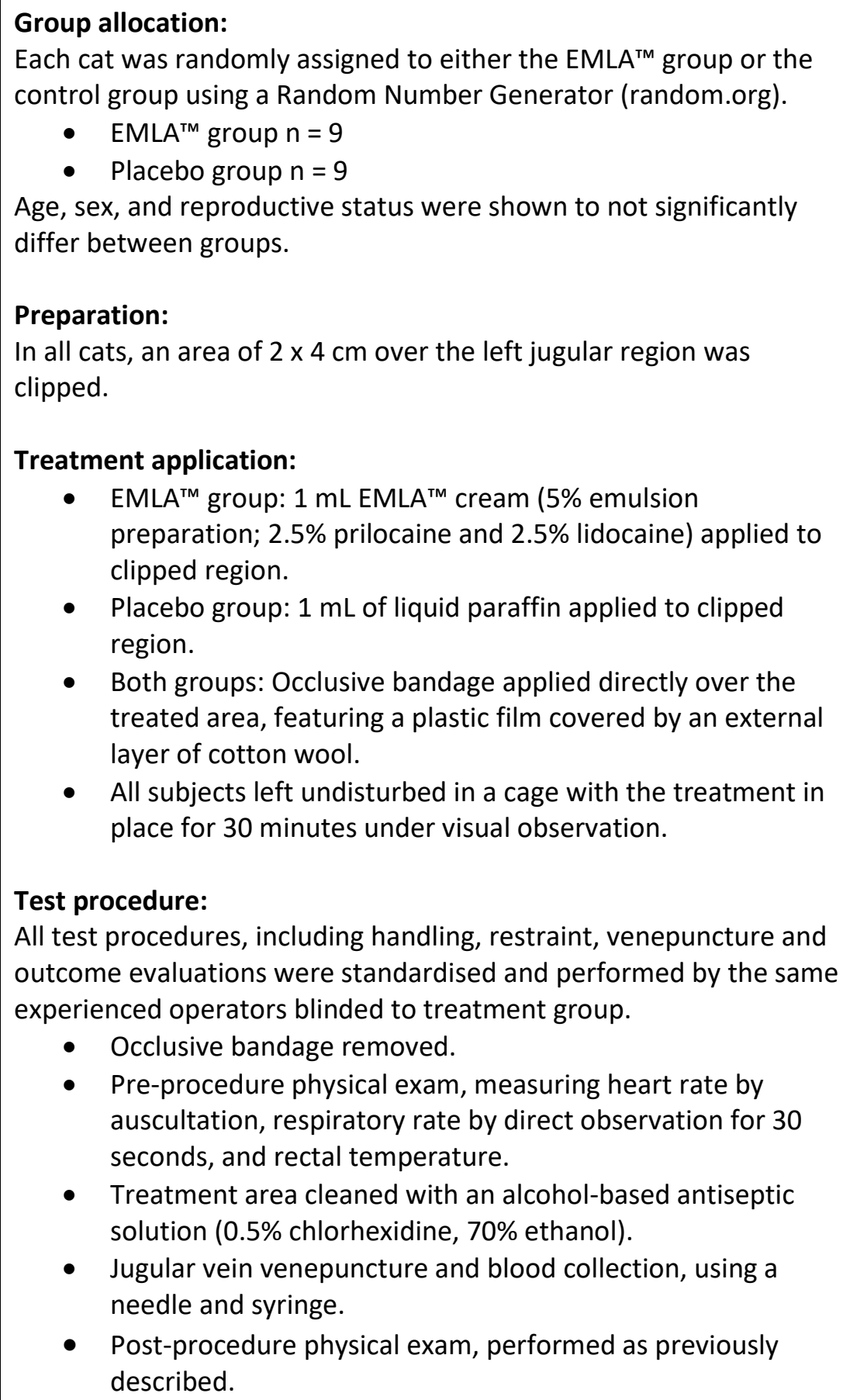 \\
\hline Study design: & Prospective, double-blind, randomised, controlled clinical trial \\
\hline Outcome studied: & $\begin{array}{l}\text { Reaction to venepuncture and handling [subjective]: } \\
\text { - Blinded operators used an adapted version of the MBPS by } \\
\text { Wagner et al. }{ }^{4} \text { to score patient stress in response to the } \\
\text { venepuncture procedure by blinded operators. }\end{array}$ \\
\hline
\end{tabular}




\begin{tabular}{|c|c|}
\hline & $\begin{array}{l}\text { Behaviours, including resistance to restraint, resistance to } \\
\text { venepuncture, vocalisation, pupil dilation, and ear } \\
\text { positioning, were assigned a numerical value. } \\
\text { Patients were given a summated stress score based on } \\
\text { behaviours performed during the procedure. } \\
\text { Ease and success of venepuncture [subjective]: } \\
\text { - The operator performing the venepuncture described the } \\
\text { - } \quad \text { The produre as 'easy' or 'difficult'. } \\
\text { up slowly and steadily, without movement of the needle in } \\
\text { the vein, and without the perforation of the back wall of the } \\
\text { vein. } \\
\text { The procedure was defined as 'difficult' if any of the 'easy' } \\
\text { criteria were not met. } \\
\text { Physiological indicators of stress [objective]: } \\
\text { Pre-procedure and post-procedure physical exam, measuring } \\
\text { respiratory rate, heart rate, and rectal temperature. } \\
\text { Local adverse reactions and procedural complications [objective]: } \\
\text { 15 minutes post-procedure, the treated area was examined for: } \\
\text { - Adverse reactions, including erythema, oedema, and/or } \\
\text { pruritus. } \\
\text { Complications related to the venepuncture, including } \\
\text { haematoma, extravasation, and/or pain. }\end{array}$ \\
\hline $\begin{array}{l}\text { Main findings: } \\
\text { (relevant to PICO question): }\end{array}$ & $\begin{array}{l}\text { - Within and between each group, heart rate, respiratory rate, } \\
\text { and temperature did not differ significantly before and after } \\
\text { venepuncture. } \\
\text { - Blood sampling was classified as 'easy' in } 1 / 9 \text { and } 8 / 9 \text { cats in } \\
\text { the Placebo and EMLA }{ }^{T M} \text { group respectively, }(P=0.015) \text {. } \\
\text { - The median stress score for the EMLA }{ }^{T M} \text { group (MED }=2 \text {; } \\
\text { range } 0-8) \text { was significantly lower compared to the placebo } \\
\text { group (MED }=6 \text {; range } 0-12)(P=0.048) \text {. } \\
\text { - } 1 / 9 \text { cats in the EMLA }{ }^{T M} \text { group performed a withdrawal } \\
\text { movement during the procedure, compared to } 7 / 9 \text { cats in } \\
\text { the control group }(P=0.015) \text {. }\end{array}$ \\
\hline Limitations: & $\begin{array}{l}\text { - Small sample size. } \\
\text { - Body weight/condition of subjects not recorded and } \\
\text { controlled as a confounding factor. } \\
\text { - Only relatively docile patients (scoring a } 2 \text { or less during } \\
\text { clinical examination) were included. } \\
\text { - Blinded operators may have been capable of distinguishing } \\
\text { EMLA }^{\mathrm{TM}} \text { cream from paraffin oil, creating a potential risk for } \\
\text { detection bias. } \\
\text { - Although kept consistent, the handling techniques used } \\
\text { were not described. } \\
\text { - Needle type and gauge not reported; volume of blood } \\
\text { collected not reported. }\end{array}$ \\
\hline
\end{tabular}




\begin{tabular}{|c|c|}
\hline \multicolumn{2}{|l|}{ Oliveira et al. $(2019)^{3}$} \\
\hline Population: & $\begin{array}{l}\text { Recruitment: } \\
\text { - Entire female cats presenting to the Universidade Federal } \\
\text { Rural do Rio de Janeiro (UFRRJ) Veterinary Teaching Hospital } \\
\text { for the purpose of ovariohysterectomy. } \\
\text { - Recruited patients were enrolled if they met eligibility and } \\
\text { inclusion criteria. } \\
\text { Criteria for eligibility and inclusion: } \\
\text { - Owned, with attainment of informed owner consent. } \\
\text { - Presented to the clinic for the purpose of an } \\
\text { ovariohysterectomy. } \\
\text { Criteria for exclusion and rejection: } \\
\text { - 'Feral' cats (undefined). } \\
\text {-Aggressive' cats (undefined). } \\
\text { Enrolled study population: } \\
\text { - } 24 \text { mixed breed cats } \\
\text { O All entire females. } \\
\text { O Age range: } 8 \text { months to } 3 \text { years. } \\
\text { O Weight range: } 2-5 k g . \\
\text { O Body condition score range (1-5 scale): } 2-4 .\end{array}$ \\
\hline Sample size: & 24 cats \\
\hline Intervention details: & 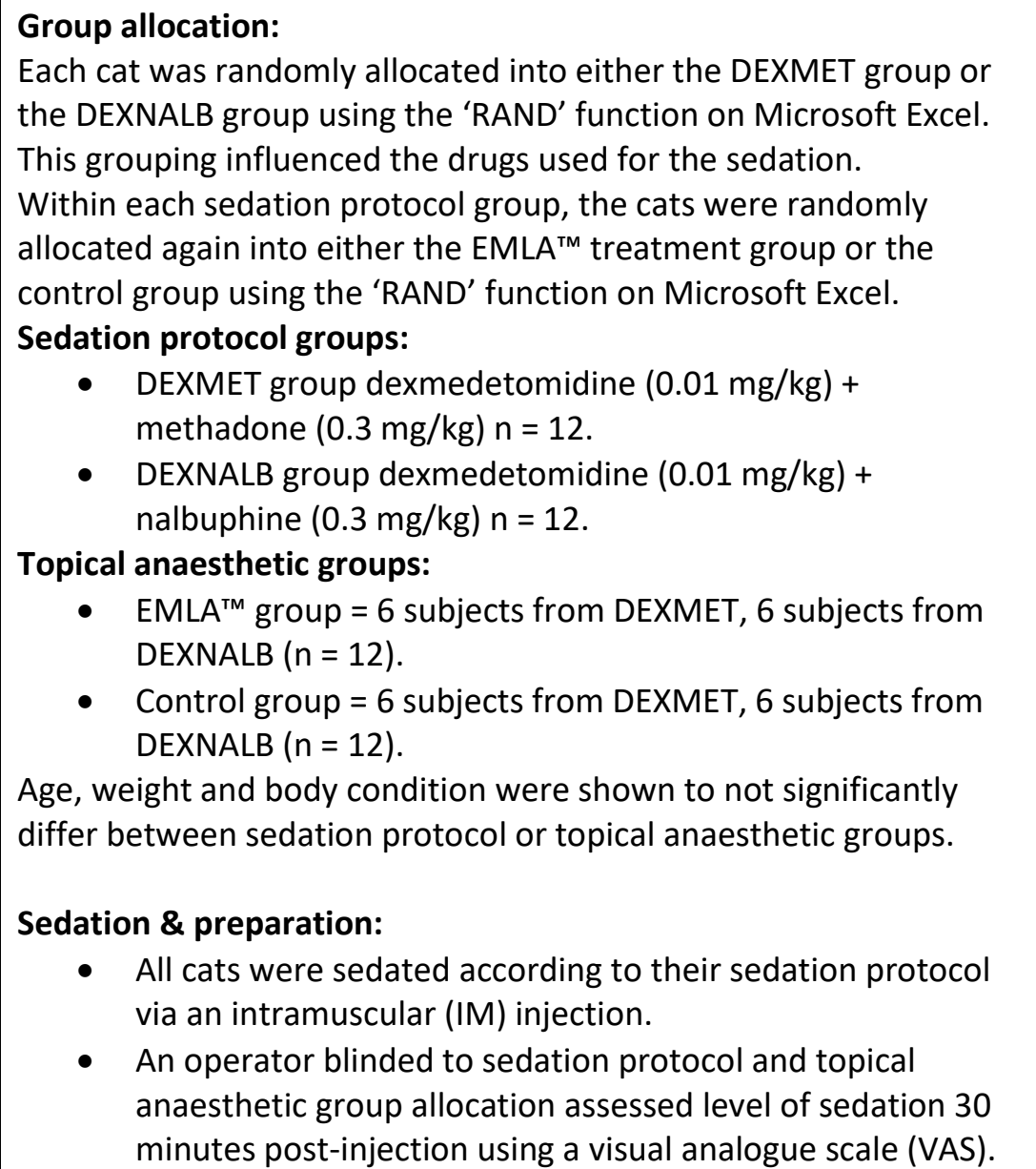 \\
\hline
\end{tabular}




\begin{tabular}{|c|c|}
\hline & $\begin{array}{l}\text { - In all cats, an area of } 2 \times 3.5 \mathrm{~cm} \text { on the left antebrachium } \\
\text { was clipped. } \\
\text { Treatment application: } \\
\text { - } \quad \text { EMLA }^{\mathrm{TM}} \text { group: } 1 \mathrm{~g} \mathrm{EMLA}^{\mathrm{TM}} \mathrm{cream} \text { ( } 5 \% \text { emulsion preparation; } \\
2.5 \% \text { prilocaine and } 2.5 \% \text { lidocaine) applied to clipped } \\
\text { region. } \\
\text { - Control group: Nothing applied to clipped region. } \\
\text { - Treatment left in place for } 20 \text { minutes. } \\
\text { Test procedure: } \\
\text { - After } 20 \text { minutes, cream (if present) was removed using } \\
\text { alcohol. } \\
\text { Clipped area disinfected with a povidone-iodine solution and } \\
\text { alcohol, repeated twice. } \\
\text { The same operator, blinded to both sedation and topical } \\
\text { anaesthetic grouping, performed cephalic vein } \\
\text { catheterisation using a } 24 \text { gauge catheter. } \\
\text { Another operator, also blinded to treatment, restrained the } \\
\text { subject, if needed, and occluded the vein during } \\
\text { catheterisation. }\end{array}$ \\
\hline Study design: & Prospective, double-blind, randomised, controlled clinical trial \\
\hline Outcome studied: & $\begin{array}{l}\text { Sedation quality [subjective]: } \\
\text { - Prior to treatment application and venepuncture, quality of } \\
\text { - } \text { sedation was assessed by a blinded operator using a VAS. } \\
\text { The VAS was a } 100 \mathrm{~mm} \text { scale with } 0 \mathrm{~mm} \text { being no sedation, } \\
\text { and } 100 \mathrm{~mm} \text { being complete sedation, whereby the cat } \\
\text { cannot be roused by noise or physical stimulation. } \\
\text { Reaction to venepuncture [subjective]: } \\
\text { - The reaction to cephalic vein catheterisation whilst sedated } \\
\text { with dexmedetomidine and either methadone or nalbuphine } \\
\text { was scored by a blinded operator during the procedure. } \\
\text { A scoring system assigned numerical values (0-3) to } \\
\text { variations of patient posture, strength of withdrawal } \\
\text { responses, degree of restraint required, demonstration of } \\
\text { aggression, and number of venepuncture attempts required } \\
\text { to achieve catheterisation. } \\
\text { Subjects were designated a total score based on behaviours } \\
\text { performed during the procedure. }\end{array}$ \\
\hline $\begin{array}{l}\text { Main findings: } \\
\text { (relevant to PICO question): }\end{array}$ & $\begin{array}{l}\text { - There was no significant difference in degree of sedation } \\
\text { between the } \mathrm{EMLA}^{\mathrm{TM}} \text { and control groups within each } \\
\text { sedation protocol group. } \\
\text { - Subjects that were treated with the EMLA }{ }^{\mathrm{TM}} \text { cream prior to } \\
\text { intravenous catheterisation had significantly lower reaction } \\
\text { scores compared to the control group subjects within the } \\
\text { same sedation protocol }(\mathrm{P}<0.05) \text {. } \\
\text { - All treatment group cats, regardless of sedation protocol, } \\
\text { had a reaction score of } 0 \text {. }\end{array}$ \\
\hline
\end{tabular}




\begin{tabular}{|l|l|}
\hline & All control cats in the DEXMET sedation group, and 5/6 cats \\
& in the DEXNALB sedation group had a reaction score of 1 or \\
& 2.
\end{tabular}

\section{Wagner et al. (2006)}

Population: Recruitment:

- Clinically ill patients presenting to the Critical Care Unit (CCU; specific hospital not declared) that had a justifiable requirement for IV catheter placement.

- Recruited patients were enrolled if they met eligibility and inclusion criteria following evaluation of patient history, physical examination, body weight, complete blood count, serum biochemistry panel, and urinalysis.

\section{Criteria for eligibility and inclusion:}

- Presented to the CCU due to clinical illness.

- Required placement of an IV jugular catheter for the treatment or management of a pre-existing clinical illness.

- Attainment of informed owner consent.

\section{Criteria for exclusion and rejection:}

- Presence of skin irritation, inflammation, or wounds on the neck region prior to venepuncture.

- Clinical evidence of shock.

- Clinical or historical evidence of anaemia (defined as packed cell volume $<25 \%$ ).

Enrolled study population:

- 31 clinically unwell cats of unknown breeds. 


\begin{tabular}{|c|c|}
\hline & $\begin{array}{l}\text { - } 23 \text { males; one entire and } 22 \text { neutered. } \\
\text { Of the } 31 \text { patients that completed the study: } \\
\text { - None were categorised as suffering from 'mild' disease. } \\
\text { - } 16 \text { were categorised as suffering from 'moderate' disease. } \\
\text { - } 15 \text { were categorised as suffering from 'severe' disease. } \\
\text { The underlying disease diagnoses included in entirety: } \\
\text { - Acute and chronic kidney failure } \\
\text { - Diabetic ketoacidosis } \\
\text { - Urinary tract obstruction } \\
\text { - } \text { Pancreatitis } \\
\text { - } \text { Liver disease } \\
\text { - } \text { Abdroenteritis }\end{array}$ \\
\hline Sample size: & 31 cats \\
\hline Intervention details: & 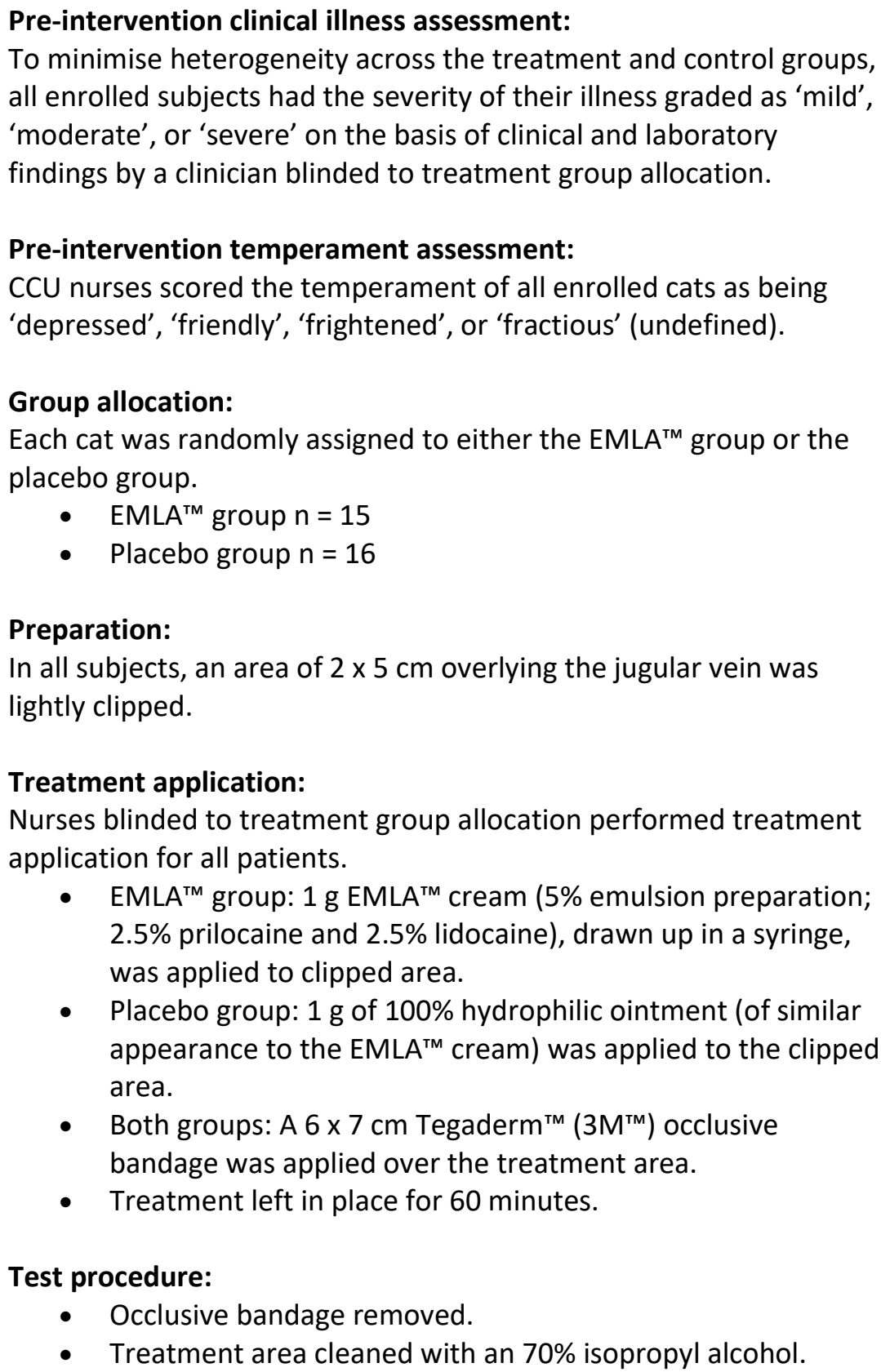 \\
\hline
\end{tabular}




\begin{tabular}{|c|c|}
\hline & $\begin{array}{l}\text { - Region re-shaved, closely, and decontaminated using a } \\
\text { 'routine sterile scrub'. } \\
\text { - Jugular venepuncture was performed using a double lumen } \\
19 \text { gauge, } 8 \text { inch jugular catheter (Paediatric Two-Lumen } \\
\text { Central Venous Catheter). } \\
\text { - All catheters were placed by one of three experienced CCU } \\
\text { nurses. }\end{array}$ \\
\hline Study design: & Prospective, double-blind, randomised, controlled clinical trial \\
\hline Outcome studied: & $\begin{array}{l}\text { Reaction to venepuncture [subjective]: } \\
\text { - The reaction to restraint and jugular vein catheterisation } \\
\text { was scored by the CCU nurse performing the procedure } \\
\text { using an adaptation of the MBPS, as described by Halperin et } \\
\text { al. (2002) }{ }^{10} \text {. } \\
\text { - } \quad \text { Behaviours including struggling, aggressive actions such as } \\
\text { hissing, scratching or biting, and types of vocalisation } \\
\text { including meowing, growling or crying, were assigned } \\
\text { numerical values. } \\
\text { - Subjects were designated a total discomfort score based on } \\
\text { behaviours performed during the procedure. } \\
\text { Success of venepuncture [subjective]: } \\
\text { - If a subject scored } 2 \text { or more in any of the categories above, } \\
\text { the procedure was stopped and the patient was sedated } \\
\text { with midazolam (0.1 mg/kg IM) and butorphanol (0.4 mg/kg } \\
\text { IM), after which catheterisation was re-attempted. } \\
\text { Catheter placement was deemed successful only if it was } \\
\text { achieved without requiring sedation. } \\
\text { Local adverse reactions [subjective]: } \\
\text { Post-procedure, the treated area was examined for: } \\
\text { - Evidence of local irritation, including blanching or erythema. } \\
\text { Systemic adverse reactions [objective \& subjective]: } \\
\text { Cats were continually observed up to } 6 \text { hours post-procedure for } \\
\text { signs of intoxication, including: } \\
\text { Vomiting, hypersalivation, diarrhoea, tremors, twitching, } \\
\text { pallor, cyanosis, tachycardia, dyspnoea. }\end{array}$ \\
\hline $\begin{array}{l}\text { Main findings: } \\
\text { (relevant to PICO question): }\end{array}$ & $\begin{array}{l}\text { - Mean scores for struggling during venepuncture were lower } \\
\text { in the } E M L A^{\mathrm{TM}} \text { group }(1.6 \pm 0.8) \text { compared to the placebo } \\
\text { group }(2.2 \pm 0.8) \text {, but not statistically significant }(P=0.06) \text {. } \\
\text { - Mean scores for aggression during venepuncture were lower } \\
\text { in the } \mathrm{EMLA}^{\mathrm{TM}} \text { group }(0.9 \pm 1.1) \text { compared to the placebo } \\
\text { group }(1.2 \pm 1.0) \text {, but not statistically significant }(P=0.51) \text {. } \\
\text { - Total discomfort scores were lower in the } \mathrm{EMLA}^{\mathrm{TM}} \text { group }(3.7 \\
\pm 2.2) \text { compared to the placebo group }(4.5 \pm 2.3) \text {, but not } \\
\text { statistically significant }(P=0.31) \text {. } \\
\text { Jugular catheter placement was achievable without sedation } \\
\text { in } 9 / 15(60 \%) \text { of } \mathrm{EMLA}^{\mathrm{TM}} \text { cats, and } 6 / 16(38 \%) \text { of placebo } \\
\text { cats, but this difference was not statistically significant }(P= \\
0.21) \text {. }\end{array}$ \\
\hline
\end{tabular}




\begin{tabular}{|l|l|}
\hline Limitations: & - Criteria to define 'clinical shock' for exclusion not reported. \\
& - Criteria for disease severity extremely difficult to \\
& standardise. \\
- & Criteria for temperament scoring not reported. \\
- & Programme/method of randomisation not reported. \\
- & The distribution of age, sex, body weight, temperament and \\
& clinical illness across each group was presented, but no $p$ - \\
& values were provided to demonstrate that there was no \\
& significant difference, thus, it cannot be assumed these \\
& factors were not confounders. \\
- Method and products used for 'routine sterile scrub' not \\
reported. \\
- Sample size too small to determine significance. \\
The authors performed a post-hoc power analysis that \\
determined that, with $\alpha=0.05$, a sample size of $n=60$ (30 \\
per group) would have been needed to determine if a \\
difference of $22 \%$ was statistically significant.
\end{tabular}

Flecknell et al. (1990) ${ }^{2}$

Population: Recruitment:

- Cats obtained from commercial breeders of laboratory animals, procured for the purpose of other, unrelated studies that necessitated the placement of a cephalic vein catheter.

Criteria for eligibility and inclusion:

- Sourced from a commercial laboratory animal breeder.

- Being used for another, unrelated study.

- Placement of a cephalic vein catheter required for the purposes of the other, unrelated study.

Enrolled study population:

- 32 cats of unknown breed:

- 10 males (reproductive status not reported).

- 26 females (reproductive status not reported).

$\circ$ Body weight $1.7 \pm 0.4 \mathrm{~kg}$.

Sample size:

32 cats

Intervention details:

Group allocation:

Each cat was assigned to either the EMLA ${ }^{\mathrm{TM}}$ group or the placebo group. No attempt to randomise allocation was reported.

- $\mathrm{EMLA}^{\mathrm{TM}}$ group $\mathrm{n}=16$

- Placebo group $n=16$

\section{Preparation:}

In all cats, an area overlying the cephalic vein was clipped.

\section{Treatment application:}

- EMLA $^{\mathrm{TM}}$ group: $1 \mathrm{~mL} \mathrm{EMLA}^{\mathrm{TM}}$ cream (5\% emulsion preparation; $2.5 \%$ prilocaine and $2.5 \%$ lidocaine), was applied to clipped area to form a $2 \mathrm{~mm}$ deep layer. 


\begin{tabular}{|c|c|}
\hline & $\begin{array}{l}\text { - Placebo group: } 1 \mathrm{~g} \text { of a bland aqueous cream was applied to } \\
\text { clipped area to form a } 2 \mathrm{~mm} \text { deep layer. } \\
\text { Both groups: An occlusive dressing was applied over the top, } \\
\text { consisting of an inner plastic wrap and an outer adhesive } \\
\text { bandage. } \\
\text { - Treatment was left in place for } 60 \text { minutes. } \\
\text { Test procedure: } \\
\text { - Occlusive dressing removed. } \\
\text { - Treatment area cleaned with isopropyl alcohol. } \\
\text { - Cephalic vein venepuncture was performed by a blinded } \\
\text { operator using a } 21 \text { gauge butterfly infusion set. }\end{array}$ \\
\hline Study design: & Prospective, double-blind, controlled experimental trial \\
\hline Outcome studied: & $\begin{array}{l}\text { Reaction to venepuncture [subjective]: } \\
\text { - Reaction to restraint and cephalic vein catheterisation was } \\
\text { scored by a second blinded operator during the procedure } \\
\text { using a simple scoring system. } \\
\text { - The scoring system allocated numerical values to body } \\
\text { tension, limb withdrawal, attempts to escape, vocalisation } \\
\text { and/or demonstration of unspecified aggressive behaviours. } \\
\text { - Subjects were assigned a total score based on behaviours } \\
\text { they performed during the procedure. }\end{array}$ \\
\hline $\begin{array}{l}\text { Main findings: } \\
\text { (relevant to PICO question): }\end{array}$ & 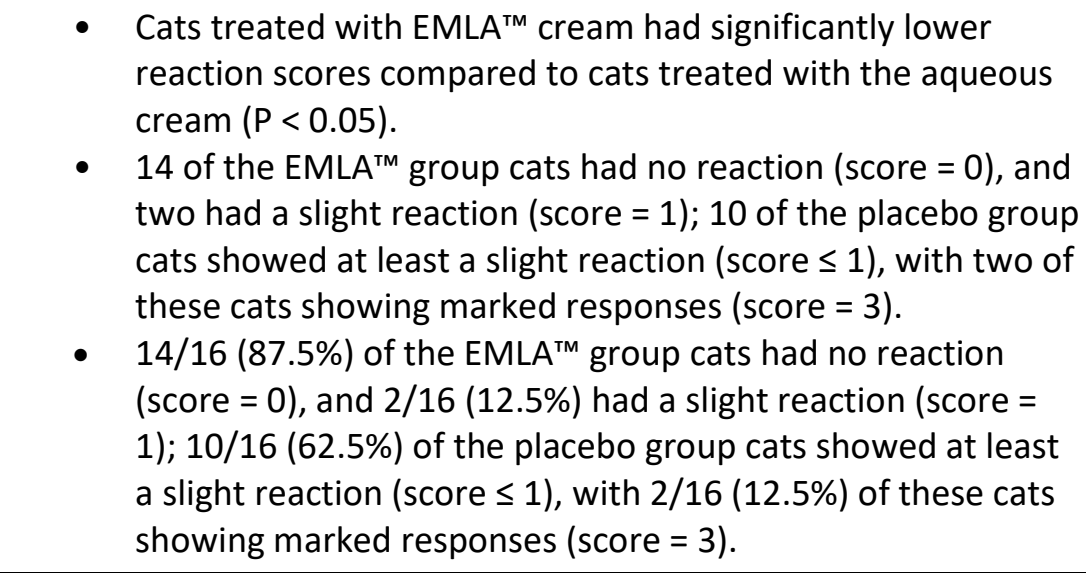 \\
\hline Limitations: & $\begin{array}{l}\text { - Age, health status, reproductive status, and temperament of } \\
\text { - Ueline subjects unknown. } \\
\text { - } \quad \text { tempernown if signalment (age, sex), body weight and } \\
\text { - No randomisation attempted. } \\
\text { - Size of area clipped for application of cream not described. } \\
\text { - Concentration of isopropyl alcohol used to sterilise the site } \\
\text { - } \quad \text { srior to venepuncture not reported. } \\
\text { - Power of sample size not calculated. }\end{array}$ \\
\hline
\end{tabular}




\section{Behaviour as a measure of pain}

In all four papers, the primary outcome measured was the response of the subjects to restraint and venepuncture, which the investigators attempted to quantify using behavioural descriptors and numerical rating scales (NRS). Therefore, the results of each study must be interpreted in the context of the inherent challenges associated not only with the accurate assessment of behaviour, but also with the use of behaviour as a measurement of pain.

The correlation between behaviour and pain is not necessarily proportional, nor consistent ${ }^{11-13}$. Pain involves both the sensation of a noxious stimuli and the provocation of an aversive emotional response ${ }^{14,15}$. Although domestic animals are known to possess the neuroanatomical apparatus and physiological components required to detect tissue damage in a way analogous to human beings, their inability to self-report means that the affective aspect of pain is very challenging to scrutinise ${ }^{6}$. This is further complicated by the myriad of confounding factors that may influence how and to what degree pain is expressed through behaviour, including species, age, health status, and other emotions such as fear ${ }^{16}$. The usefulness of behaviour as a definitive measure of pain is greatly challenged by the fact that many behaviours used as proxies for pain are also induced by emotions such as fear, even in the absence of actual tissue damage ${ }^{6,17}$.

\section{Feline-specific pain behaviours}

Given that behaviour is strongly influenced by the evolutionary history of the species, it is essential to assess and interpret behaviours in a species-specific context ${ }^{17,19,20}$. The study by Flecknell et al. ${ }^{2}$ aimed to measure pain in multiple species, including dogs, cats, rabbits, and rats. The NRS designed by Flecknell et al. ${ }^{2}$, therefore, used very basic behavioural responses that are conserved across species despite having divergent ethograms. Consequently, it is possible that more nuanced signs of discomfort expressed specifically by cats, such as purring, growling, posturing, ear positioning, pupil dilation, and facial tension ${ }^{17,20}$, were overlooked, resulting in erroneously low discomfort scores ${ }^{21}$.

A similar scoring system was adopted by Oliveira et al. ${ }^{3}$, however, the implication of this is unique because all subjects were sedated at the time of venepuncture. Assuming that a sedated cat is more likely to demonstrate simple and reflex-like responses to pain, such as limb withdrawal, rather than complex responses, such as hissing ${ }^{22}$, it could be purported that the use of a simple NRS is not detrimental. However, it can also be argued that the analgesic, sedative and muscle-relaxing effects of the opioids and $\alpha_{2}$-agonists used in the sedation protocols may have impacted the ability of the subjects to physically react to any noxious stimuli detected ${ }^{3,22}$. It should be noted that the use of sedation does not invalidate the significance of the outcomes measured by Oliveira et al. ${ }^{3}$ because both the treatment and control groups were reportedly sedated to an equal degree, and yet there was still a significant difference in the reactivity to venepuncture. A study in children likewise found that although pain caused by venepuncture was reduced with the use of systemic opioids, the application of EMLA ${ }^{\mathrm{TM}}$ cream at the site of venepuncture still produced a measurable and significant difference in the degree of discomfort experienced ${ }^{23}$.

The NRS used by Wagner et al. ${ }^{4}$ and Crisi et al. ${ }^{1}$ was adapted from the Modified Behavioural Pain Scale $(\mathrm{MBPS})^{10,24}$. This was originally developed by paediatric clinicians to evaluate postoperative pain ${ }^{24}$ and was later used to assess pain during venepuncture in children ${ }^{25,26}$. Although it featured a comparatively more representative sample of feline-specific behaviours related to discomfort, such as attempting to scratch or bite, ear positioning, growling or hissing ${ }^{16}$, no literature or methodology was cited to explain how or why certain behaviours were selected. Furthermore, these revised versions of the MBPS have not been validated as an accurate measure of pain in cats.

A systematic review by Merola \& Mills ${ }^{16}$ described an ideal NRS as one that is highly sensitive and has minimal variability across observers, conditions, and subjects in which pain is being assessed. While the majority of 
studies appraised by the review utilised an NRS to measure feline pain, only the UNESP-Botucatu Multidimensional Composition Pain Scale was found to demonstrate good validity, reliability and sensitivity ${ }^{6}$. All four papers, thus, could have benefited from incorporating all or part of the UNESP-Botucatu Multidimensional Composition Pain Scale into their methodology ${ }^{16,21,27-29}$.

\section{Age as a confounding factor}

In cats, age has been implicated as a factor that may influence the behavioural expression of pain ${ }^{18}$. The study designs by Crisi et al. ${ }^{1}$ and Oliveira et al. ${ }^{3}$ attempted to control this confounder by evidencing that age did not differ significantly between the randomised treatment groups. In comparison, Wagner et al. ${ }^{4}$ and Flecknell et al. $^{2}$ failed to demonstrate the absence, or presence, of any significant difference in age between treatment groups by way of statistical analysis. Moreover, the study by Flecknell et al. ${ }^{2}$ did not report any randomisation of subjects for allocation to treatment groups, which reduces the strength of evidence by permitting confounding bias $^{30}$.

Performing a paired analysis whereby each subject was tested both with and without the EMLA ${ }^{\mathrm{TM}}$ cream on different occasions and comparing their reactions may have achieved better control over innate inter-subject behavioural differences ${ }^{30}$. However, such a design has its own limitations with regard to minimising other confounding factors in between procedures ${ }^{31}$, and would have decreased the degree of study design refinement. In all studies, except Crisi et al. ${ }^{1}$, patients were only enrolled if they had a non-related indication for venepuncture, which would be much more challenging to achieve for a paired analysis design, potentially generating exclusion bias $^{30}$.

\section{Fear as a confounding factor}

In a conscious animal, a noxious stimulus may not be the only factor contributing to the expression of painassociated behaviours ${ }^{32}$. Indeed, many of the behaviours used by these studies as criteria for quantifying pain are also recognised as fear responses in cats ${ }^{33}$. It is well established that many feline patients become readily fearful during veterinary visitation, even when pain-free ${ }^{17,33}$. Often, this is triggered by prior negative experiences, physical restraint, and/or the presence of frightening sensorium, such as unfamiliar sounds, sights and smells ${ }^{20,32,33}$. As such, these stimuli must be considered confounding factors but are highly impractical for clinical researchers to exclude.

Both Crisi et al. ${ }^{1}$ and Oliveira et al. ${ }^{3}$ attempted to mitigate the impact of inherent fearfulness as a confounding factor by excluding subjects that were resistant to handling during clinical examination, or were deemed "aggressive" by the clinician, respectively. While the method utilised by Crisi et al. ${ }^{1}$ for identifying and rejecting reactive subjects was well-defined and repeatable, the impact of excluding 'feral' and 'aggressive' subjects in the paper by Oliveira et al. ${ }^{3}$ is unknown as neither of the terms were specifically defined and could have various interpretations.

It should be noted, however, that the behavioural threshold employed by Crisi et al. ${ }^{1}$ is quite intolerant, requiring patients to demonstrate minimal to no fear associated with clinical examination for inclusion. While this improves the internal validity of the study by creating a narrow behavioural baseline amongst its study population, it simultaneously decreases its external validity. That is, the results cannot be well extrapolated to a population in which most feline patients that would typically demonstrate even a modest degree of fear (i.e., score of 2 or greater using the system ${ }^{1}$ employed by Crisi et al. ${ }^{1}$ ) when presented to a veterinary clinic.

The validity of all studies could be improved by firstly performing a pilot study to characterise the range and distribution of temperaments in the target population, and subsequently enrolling a large and representative sample.

Given that the studies by Wagner et al. ${ }^{4}$ and Flecknell et al. ${ }^{2}$ did not exclude subjects based on temperament, it is possible that their results are more indicative of the efficacy of EMLA ${ }^{\mathrm{TM}}$ cream in fearful or aggressive 
patients. However, this is impossible to verify as neither study reported nor integrated analysis of preintervention temperament into their design, which is a significant limitation.

Furthermore, the study by Flecknell et al. ${ }^{2}$ is greatly limited by its lack of pre-intervention temperament scoring because its subjects were laboratory animals acquired from specific breeders. As such, it would be valuable to know if these felines were more or less fractious than the general population.

In humans, it has been shown that the relationship between degree of tissue damage and the experience of pain is not linear and may be impacted by the emotional context ${ }^{12,15}$. That is, even a procedure that creates a consistent degree of tissue trauma may induce different degrees of pain in a patient depending on their emotional state at the time ${ }^{12,15}$. This implies that the emotional domain of pain should not be ignored when attempting to improve patient welfare ${ }^{6}$ and lends credence to the use of techniques that make procedures inherently less stressful for patients ${ }^{33}$.

Only the study by Crisi et al. ${ }^{1}$ reported attempts to minimise iatrogenic fear, anxiety or distress by keeping subjects in separate and quiet waiting areas and allowing subjects to rest undisturbed between treatment application and venepuncture ${ }^{32,33}$. None of the studies, however, described in detail the techniques used for the handling and restraint of subjects during patient preparation, treatment application, and venepuncture. This is significant because poor handling techniques may have contributed to patient stress, which could have increased the likelihood of resistance, vocalisation, or other behaviours that were being assessed as measures of pain $16,18,32,33$. In the study by Oliveira et al. ${ }^{3}$, the impact of stress or fear on the demonstration of pain is less likely to be a confounding factor because patients were sedated during all procedures, and so the reaction to venepuncture is more likely to represent the sensation and reflex response to pain ${ }^{22,23}$.

\section{Health as a confounding factor}

It is well known that illness and disease can alter animal behaviour ${ }^{34}$, the mechanism of which can vary widely depending on the nature and severity of the disease. An animal that is obtunded or stuporous, weak, or lethargic secondary to severe systemic disease will likely have reduced responses to all kinds of stimuli, including the focal pain induced by venepuncture. As such, health should be considered as a confounding factor when behaviour is used to measure outcomes.

The study by Wagner et al. ${ }^{4}$ specifically only recruited subjects that were critically unwell, such that they had a medical indication for jugular vein catheterisation. It is possible that the lack of statistical significance difference in pain responses between $\mathrm{EMLA}^{\mathrm{TM}}$ cream-treated subjects and controls may be related to the fact that all subjects were either moderately or severely unwell, and therefore unable to respond as vigorously to pain as they normally would.

The study by Flecknell et al. ${ }^{2}$ utilised subjects that required catheterisation for other research projects, but the health status of these subjects was not disclosed.

\section{Subjective measurement and assessment}

The appraisal of a behaviour and its magnitude is subjective, and therefore will differ between operators and be influenced by their ability to recognise behaviours based on training or familiarity with the species ${ }^{16}$. Flecknell et al. ${ }^{2}$ and Oliveira et al. ${ }^{3}$ minimised the impact of inter-operator variability by using a single, blinded operator to evaluate all patients, whereas Wagner et al. ${ }^{4}$ had three assessors, and Crisi et al. ${ }^{1}$ had an unspecified number of assessors. None of the papers stated the use of an operator that was specialised or trained in feline ethology.

Despite the challenges associated with using behaviour as a measurement of pain, particularly in the context of recording accurate and reliable results for a scientific study, observation of behaviour is still regarded the 
most effective way to measure pain in cats, even when compared to objective physiological parameters such as heart rate, respiratory rate, or blood pressure $\mathrm{e}^{16,17,35}$.

\section{Operator blinding}

Blinding is a crucial method for minimising the impact of selection bias on results ${ }^{36}$, and was apparently performed in all four studies ${ }^{1-4}$. Notably, paraffin oil was used as the placebo for the control group in the study by Crisi et al. ${ }^{1}$, which the blinded operators may have been able to distinguish from the EMLA ${ }^{\mathrm{TM}}$ cream, and no placebo was used in the study by Oliveira et al. ${ }^{3}$. In both studies, the methodologies do not specifically describe if the blinded operators performing the evaluation were also responsible for removing the occlusive bandage and cleaning the site immediately prior to venepuncture, in which case treatment group subjects may have been discernible from controls. In comparison, both Flecknell et al. ${ }^{2}$ and Wagner et al. ${ }^{4}$ specify the use of an aqueous cream that closely resembles the $\mathrm{EMLA}^{\mathrm{TM}}$ cream in the control groups.

\section{Sample size}

Sample size is a critical consideration for all scientific research as it impacts the ability of a study design to significantly detect a true difference between treatments ${ }^{37}$. A sample size power calculation should be performed during the planning phase, as an inadequate sample size results in an increased type II error rate and reduced validity, while an excessively large sample is considered wasteful and thus unethical ${ }^{37}$. Although both Crisi et al. ${ }^{1}$ and Wagner et al. ${ }^{4}$ claim to have performed a sample size power calculation with data from previous studies, the means and standard deviations used in these calculations were not reported and so their results cannot be externally verified, and post-hoc power analysis is not generally recommended ${ }^{38}$.

In the study by Wagner et al. ${ }^{4}$, the authors described their sample size as a potential limitation. Their preliminary calculation factored in a clinically meaningful difference of $50 \%$, such that their sample size was ultimately insufficient for determining if the $22 \%$ difference in sedation rates detected between the treatment groups was significant or not.

The studies by Oliveira et al. $^{3}$ and Flecknell et al. ${ }^{2}$ did not report any sample size calculation and so the adequacy of their samples cannot be substantiated.

\section{Procedural confounding factors}

Beyond the challenges associated with outcome measurement, certain differences in methodology between the four studies also warrant consideration as confounders. These include differences in the control of skin integrity and overall patient health; procedure site (i.e., jugular vein compared to cephalic vein); site preparation method; occlusive dressing and contact time; venepuncture type (i.e., blood collection compared to catheterisation); and venepuncture equipment (i.e., needle or catheter length, material and gauge). Importantly, these variations in methodology do not necessarily diminish the strength of the evidence as long as they are appropriately considered as potential confounders when interpreting the study results ${ }^{30}$.

\section{Application}

When interpreting the clinical applicability of the reviewed evidence, the principles of transdermal pharmacokinetics must be highlighted in the context of the methodologies employed. The efficacy of EMLA ${ }^{\mathrm{TM}}$ cream in achieving localised pain relief relies firstly on adequate absorption of its constituents, lidocaine and prilocaine, through the integument. Transdermal absorption is impacted by a number of patient factors including but not limited to the integrity, thickness, composition, and vascularity of the skin, as well as the core temperature and the presence or absence of local or systemic disease ${ }^{39,40}$.

The integrity of the stratum corneum layer of the skin influences its ability to act as a physical barrier, and this can be impacted by laceration, abrasion, maceration, or inflammation ${ }^{39,41,42}$. To control for this, the studies by 
Crisi et al. ${ }^{1}$ and Wagner et al. ${ }^{4}$ specifically excluded patients that presented with signs of trauma or irritation over the testing area prior to venepuncture. It should be noted that even the process of clipping hair can remove layers of the stratum corneum and improve transdermal absorption. As such, applying EMLA ${ }^{\mathrm{TM}} \mathrm{cream}$ to a region that has been thoroughly clipped is likely important for efficacy in practice ${ }^{43}$.

The thickness of feline skin ranges between 0.4 to $2 \mathrm{~mm}$, and is known to vary across anatomical sites, with the skin being thickest across the dorsum and thinner along the ventrum ${ }^{40,41,44}$. It is anecdotally reported that adult entire male cats have thicker skin, which could impact transdermal absorption, but no peer-reviewed evidence to support this claim was found. Although the study by Crisi et al. ${ }^{1}$ did have three entire males enrolled and distributed across both the treatment and control groups, this is unlikely to be a large enough sample to definitively demonstrate the same degree of $\mathrm{EMLA}^{\mathrm{TM}}$ cream efficacy in entire male cats compared to females or neutered males.

The density of blood vessels and adnexa, such as hair follicles and sebaceous glands, also varies across sites and can impact on the absorption and systemic distribution of transdermal drugs ${ }^{39,40}$. Unfortunately, there are no current studies at time of writing that compare the histology of skin from the ventral neck over the jugular vein to the dorsal surface of antebrachium over the cephalic vein in felines, and thus the influence of these factors in the context of $\mathrm{EMLA}^{\mathrm{TM}}$ cream application for the purpose of venepuncture pain-relief remains speculative.

The contact time required before efficacy is achieved is partially related to the transdermal absorption, but also related to subsequent distribution ${ }^{39,40,43}$. If the drug is rapidly taken up into the bloodstream, it may require an increased dose to achieve local levels high enough for efficacy, thus necessitating increased contact time $^{39,40,43}$. By comparison, if there is reduced distribution due to dermal sequestration or reduced vascularity, then the contact time required may be shorter ${ }^{39,40,43}$. The paper by Oliveira et al. ${ }^{3}$ demonstrated that 20 minutes of contact time was sufficient to produce significantly different pain responses, despite the fact that the manufacturer of EMLA ${ }^{\mathrm{TM}}$ cream recommends 60 minutes contact time. The authors purported that this may be a consequence of the vasoconstriction induced by the dexmedetomidine given as part of the sedation protocol. In practice, other conditions or drugs known to induce vasoconstriction may produce similar results.

\section{Safety \& adverse effects}

Lidocaine and prilocaine are known to have potential local and systemic adverse effects ${ }^{45}$. Cats are more sensitive to systemic lidocaine compared to dogs, with lower-level toxic doses inducing convulsions, and higher doses inducing arrythmias, cardiovascular collapse and death ${ }^{45,46}$. However, multiple studies have demonstrated that, when applied topically, the absorption of lidocaine into systemic circulation is very poor, resulting in plasma concentrations well below the documented levels of toxicity ${ }^{5,47-49}$. Similarly, although prilocaine has been associated with the formation of methaemoglobin in children, a study demonstrated no methaemoglobinaemia in feline patients following use of $\mathrm{EMLA}^{\mathrm{TM}} \mathrm{cream}^{5}$. Furthermore, the local side effects of topical lidocaine commonly observed in humans, such as blanching, oedema and erythema of the skin $^{50,51}$, have not been reported in cats ${ }^{5,47-49}$. Given that transmucosal absorption is significantly different to transdermal absorption, there may be some risk of adverse effects if the EMLA ${ }^{\mathrm{TM}}$ cream is ingested or comes in contact with oral mucosa, however, this can be prevented by applying an occlusive bandage. Overall, it is concluded that EMLA ${ }^{\mathrm{TM}}$ cream, when applied according to manufacturer's instructions, appears to be a safe, non-invasive method for achieving local anaesthesia in cats during venepuncture ${ }^{1,2,5}$.

\section{Clinical application}

The effective mitigation of iatrogenic pain is both an ethical and professional obligation, and should be central to all veterinary procedures, rather than adjunctive. When a method of veterinary intervention is known or assumed to be painful, veterinarians must strive to anticipate and prevent pain, particularly in nonemergency situations. 
The short-term goal of integrating EMLA $^{\mathrm{TM}}$ cream into routine practice is to minimise pain associated with venepuncture - a common and valuable procedure - and long-term to avoid the provocation of stress in feline patients, provide more positive clinical experiences, and improve patient-client-veterinarian relationships. However, reducing stress in feline veterinary practice patients is a multi-faceted challenge that warrants a multi-modal approach. Although $\mathrm{EMLA}^{\mathrm{TM}}$ cream represents an easy, safe and effective method for reducing venepuncture-associated pain, its usefulness in isolation is limited. Given that the affective state of the patient, to begin with, significantly influences the experience of pain ${ }^{6}, \mathrm{EMLA}^{\mathrm{TM}}$ cream (and other wellevidenced and feline-specific pain management strategies), should be employed in combination with lowstress handling techniques and husbandry practices ${ }^{7}$.

The 30 minute application time represents the most likely barrier to the widespread adoption of EMLA ${ }^{\mathrm{TM}}$ cream use in practice. For an in-consultation venepuncture procedure, the contact time requirement may necessitate a short period of hospitalisation and it is important to consider whether the stress of doing so will negate any benefit gained from achieving a 'pain-free' venepuncture experience. Thus, it is the author's opinion that the use of EMLA ${ }^{\mathrm{TM}}$ cream is most valuable for relieving pain and reducing stress in hospitalised cats. Aside from emergency situations, the majority of indications for venepuncture in hospitalised patients can be anticipated (e.g., catheterisation for a scheduled surgery; blood collection for biochemical analysis following a period of intravenous fluid therapy, etc.) and thus preparing for the procedure 30 minutes prior with EMLA ${ }^{\mathrm{TM}}$ cream application should not be inhibitive.

\section{Reflection}

Overall, the study by Crisi et al. ${ }^{1}$ demonstrates moderate evidence that the use of EMLA ${ }^{\mathrm{TM}}$ cream significantly reduces the signs of pain associated with venepuncture in healthy feline patients with a 30-minute application time. Although its findings cannot be extrapolated to conscious patients, the study by Oliveira et al. ${ }^{3}$ also provides moderate evidence of EMLA $^{\mathrm{TM}}$ cream efficacy in reducing pain responses associated with venepuncture in sedated feline patients. The study by Wagner et al. ${ }^{4}$ demonstrated a trend towards reduced pain responses in clinically unwell felines treated with EMLA ${ }^{\mathrm{TM}}$ cream during venepuncture, although the difference was not significant and so the strength of evidence is not as great. Conversely, while the evidence presented by Flecknell et al. ${ }^{2}$ showed significantly lower pain responses in the treatment group, the quality of evidence is limited by the experimental setting, which reduces external validity, and lack of randomisation, which may have increased confounding bias.

Given that all four studies are weakened by various limitations, a further study using a much larger population, using healthy patients of various temperaments, and a valid, standardised pain scale would be valuable.

\section{Methodology Section}

\begin{tabular}{|c|c|}
\hline \multicolumn{2}{|l|}{ Search Strategy } \\
\hline $\begin{array}{r}\text { Databases searched and dates } \\
\text { covered: }\end{array}$ & $\begin{array}{l}\text { CAB Abstracts via Web of Science 1910-2021 } \\
\text { Medline via Ovid 1946-2020 }\end{array}$ \\
\hline Search terms: & $\begin{array}{l}\text { CAB Abstracts: } \\
\text { ((cat OR cats OR feline* OR felid*) AND (puncture OR venepuncture } \\
\text { OR venipuncture OR phlebotomy OR intravenous OR injection OR } \\
\text { catheter OR catheterisation OR catheterization OR cannula OR } \\
\text { cannulisation OR cannulization OR cannulation OR blood OR jugular } \\
\text { OR cephalic OR saphenous OR vein OR venous OR artery OR arterial) } \\
\text { AND (lignocaine OR lidocaine OR prilocaine OR xylocaine OR amino } \\
\text { amide OR eutectic OR EMLA OR anesthesia OR anesthetic OR }\end{array}$ \\
\hline
\end{tabular}


anaesthesia OR anaesthetic) AND (local* OR topical* OR

transdermal)).

Medline:

((cat OR cats OR feline* OR felid*) AND (puncture OR venepuncture $O R$ venipuncture $O R$ phlebotomy $O R$ intravenous $O R$ injection $O R$ catheter OR catheterisation OR catheterization OR cannula OR cannulisation OR cannulization OR cannulation OR blood OR jugular $O R$ cephalic $O R$ saphenous $O R$ vein $O R$ venous $O R$ artery $O R$ arterial) AND (lignocaine OR lidocaine OR prilocaine OR xylocaine OR amino amide OR eutectic OR EMLA OR anesthesia OR anesthetic OR anaesthesia OR anaesthetic) AND (local* OR topical* OR transdermal)).

Dates searches performed: 27 Apr 2021

\section{Exclusion / Inclusion Criteria}

Exclusion: - Papers older than 30 years, for the purposes of evaluating the most recent evidence.

- Not related to the PICO parameters (non-felid patients; nonlidocaine agents; agents administered by non-topical routes; non-venepuncture procedures, study designs not focused on measuring pain responses)

- Systematic reviews

- Case studies

- Book chapters

- Conference proceedings

Inclusion: Randomised, controlled studies.

Feline subjects $>6$ months age (younger than this generally requires different dosage regimes ${ }^{52}$ ); topically-applied anaesthetic products containing lidocaine (pure or in a mixture).

\begin{tabular}{|c|c|c|c|c|c|c|c|c|}
\hline \multicolumn{9}{|c|}{ Search Outcome } \\
\hline Database & $\begin{array}{c}\text { Number } \\
\text { of } \\
\text { results }\end{array}$ & $\begin{array}{c}\text { Excluded } \\
- \\
>30 \\
\text { years old }\end{array}$ & $\begin{array}{c}\text { Excluded } \\
- \\
\text { Reviews }\end{array}$ & $\begin{array}{c}\text { Excluded } \\
- \\
\text { Case } \\
\text { studies }\end{array}$ & $\begin{array}{c}\text { Excluded } \\
- \\
\text { Book } \\
\text { chapters }\end{array}$ & $\begin{array}{c}\text { Excluded } \\
- \\
\text { Conference } \\
\text { proceedings }\end{array}$ & $\begin{array}{c}\text { Excluded } \\
- \\
\text { Does not } \\
\text { answer } \\
\text { PICO }\end{array}$ & $\begin{array}{c}\text { Total } \\
\text { relevant } \\
\text { papers }\end{array}$ \\
\hline $\begin{array}{l}\text { CAB } \\
\text { Abstracts }\end{array}$ & 119 & 24 & 20 & 9 & 11 & 5 & 46 & 4 \\
\hline Medline & 400 & 208 & 12 & 10 & 0 & 0 & 166 & 4 \\
\hline \multicolumn{8}{|c|}{ Total relevant papers when duplicates removed } & 4 \\
\hline
\end{tabular}


The authors declare no conflict of interest.

I would like to thank Dr. Anne Quain (https://orcid.org/0000-0002-5122-0068) for providing academic guidance.

\section{REFERENCES}

1. Crisi, P. E., De Santis, F., Giordano, M. V., Cerasoli, I., Colucci, F., Di Tommaso, M. \& Luciani, A. (2020) Evaluation of eutectic lidocaine/prilocaine cream for jugular blood sampling in cats. Journal of Feline Medicine and Surgery. 23(2), 185-189. DOI: https://doi.org/10.1177/1098612X20917309

2. Flecknell, P.A., Liles, J.H. \& Williamson, H.A. (1990). The use of lignocaine-prilocaine local anaesthetic cream for pain-free venepuncture in laboratory animals. Laboratory Animals. 24(2), 142-146.

DOI: https://doi.org/10.1258/002367790780890121

3. Oliveira, R. L. S., Soares, J. H. N., Moreira, C. M. R., Silva, C. P. P., Carrasco, L. P. S. \& Souza, H. J. M. (2019). The effects of lidocaine-prilocaine cream on responses to intravenous catheter placement in cats sedated with dexmedetomidine and either methadone or nalbuphine. Veterinary Anaesthesia and Analgesia. 46(4), 492-495. DOI: https://doi.org/10.1016/j.vaa.2019.03.005

4. Wagner, K.A., Gibbon, K.J., Strom, T.L., Kurian, J.R. \& Trepanier, L.A. (2006). Adverse effects of EMLA (lidocaine/prilocaine) cream and efficacy for the placement of jugular catheters in hospitalized cats. Journal of Feline Medicine and Surgery. 8(2), 141-144.

DOI: https://doi.org/10.1016/i.jfms.2005.10.002

5. Gibbon, K.J., Cyborski, J.M., Guzinski, M.V., Viviano, K.R. \& Trepanier, L.A. (2003). Evaluation of adverse effects of EMLA (lidocaine/prilocaine) cream for the placement of jugular catheters in healthy cats. Journal of Veterinary Pharmacology and Therapeutics. 26(6), 439-441.

DOI: https://doi.org/10.1046/i.0140-7783.2003.00536.x

6. Merola, I. \& Mills, D.S. (2016). Systematic review of the behavioural assessment of pain in cats. Journal of Feline Medicine and Surgery. 18(2), 60-76 DOI: https://doi.org/10.1177/1098612x15578725

7. Lloyd, J.K.F. (2017). Minimising Stress for Patients in the Veterinary Hospital: Why It Is Important and What Can Be Done about It. Veterinary Sciences. 4(2), 22.

DOI: https://dx.doi.org/10.3390\%2Fvetsci4020022

8. Roudebush, P., Allen, T.A., Dodd, C.E. \& Novotny, B.J. (2004). Application of evidence-based medicine to veterinary clinical nutrition. Journal of the American Veterinary Medical Association. 224(11), 17651771. DOI: https://doi.org/10.2460/javma.2004.224.1766

9. Lloret, A. (2009). The process of evidence-based medicine. Journal of Feline Medicine and Surgery. 11(7). 529-529. DOI: https://doi.org/10.1016\%2Fj.jfms.2009.05.001

10. Halperin, B. A., Halperin, S. A., McGrath, P., Smith, B. \& Houston, T. (2002). Use of lidocaine-prilocaine patch to decrease intramuscular injection pain does not adversely affect the antibody response to diphtheria-tetanus-acellular pertussis-inactivated poliovirus - Haemophilus influenzae type $b$ conjugate and hepatitis $B$ vaccines in infants from birth to six months of age. The Pediatric Infectious Disease Journal, 21(5), 399-405. DOI: https://doi.org/10.1097/00006454-200205000-00010

11. Cambridge, A.J., Tobias, K.M., Newberry, R.C. \& Sarkar, D.K. (2000). Subjective and objective measurements of postoperative pain in cats. Journal of the American Veterinary Medical Association. 217(5), 685-690. DOI: https://doi.org/10.2460/javma.2000.217.685

12. Fernandez, E, \& Turk, D. (1992). Sensory and affective components of pain: Separation and synthesis. Psychological Bulletin. 112(2), 205-217. DOI: https://psycnet.apa.org/doi/10.1037/00332909.112.2.205

13. Merola, I. \& Mills, D.S. (2016). Systematic review of the behavioural assessment of pain in cats.Journal of Feline Medicine and Surgery. 18(2), 60-76. DOI: https://doi.org/10.1177/1098612X15578725 
14. Zhang, X-J., Zhang, T-W., Hu, S-J. \& Xu, H. (2011). Behavioral assessments of the aversive quality of pain in animals. Neuroscience Bulletin. 27, 61-67. DOI: https://dx.doi.org/10.1007\%2Fs12264-011$\underline{1035-3}$

15. Lumley, M. A., Cohen, J. L., Borszcz, G. S., Cano, A., Radcliffe, A. M., Porter, L. S., Schubiner, H. \& Keefe, F. J. (2011). Pain and emotion: a biopsychosocial review of recent research. Journal of Clinical Psychology. 67(9), 942-968. DOI: https://doi.org/10.1002/jclp.20816

16. Merola, I. \& Mills, D.S. (2016). Behavioural Signs of Pain in Cats: An Expert Consensus. PloS One. DOI: https://doi.org/10.1371/journal.pone.0150040

17. Grant, D. (2001). Recognising Pain in Small Animals. Veterinary Nursing Journal. 16(6), 209-212. DOI: https://doi.org/10.1080/17415349.2001.11013184

18. Epstein, M. E., Rodan, I., Griffenhagen, G., Kadrlik, J., Petty, M. C., Robertson, S. A. \& Simpson, W. (2015). 2015 AAHA/AAFP Pain Management Guidelines for Dogs and Cats. Journal of Feline Medicine and Surgery. 17(3), 251-272. DOI: https://doi.org/10.1177/1098612x15572062

19. Paul-Murphy, J., Ludders, J. W., Robertson, S. A., Gaynor, J. S., Hellyer, P. W. \& Wong, P. L. (2004). The need for a cross-species approach to the study of pain in animals. Journal of the American Veterinary Medical Association. 224(5), 692-697. DOI: https://doi.org/10.2460/javma.2004.224.692

20. Rodan, I. (2010). Understanding Feline Behavior and Application for Appropriate Handling and Management. Topics in Companion Animal Medicine. 25(4), 178-188.

DOI: https://doi.org/10.1053/j.tcam.2010.09.001

21. Brondani, J., Mama, K., Luna, S. P., Wright, B., Niyom, S., Ambrosio, J., Vogel, P. \& Padovani, C. (2013). Validation of the English version of the UNESP-Botucatu multidimensional composite pain scale for assessing postoperative pain in cats. BMC Veterinary Research. 9, 143.

DOI: https://doi.org/10.1186/1746-6148-9-143

22. Nagore, L., Soler, C., Gil, L., Serra, I., Soler, G. \& Redondo, J. I. (2013). Sedative effects of dexmedetomidine, dexmedetomidine-pethidine and dexmedetomidine-butorphanol in cats. Journal of Veterinary Pharmacology and Therapeutics. 36(3), 222-228. DOI: https://doi.org/10.1111/i.13652885.2012.01405.x

23. Hopkins, C.S., Buckley, C.J. \& Bush, G.H. (1988). Pain-free injection in infants. Use of a lignocaineprilocaine cream to prevent pain at intravenous induction of general anaesthesia in 1-5-year-old children. Anaesthesia. 43(3), 198-201. DOI: https://doi.org/10.1111/j.1365-2044.1988.tb05539.x

24. McGrath, J.P., Johnson, T.G., Goodman, T.J. \& Schillinger, T.J. (1984). The development and validation of a behavioral pain scale for children: The children's hospital of eastern ontario pain scale (CHEOPS). Pain. 18(S24). DOI: https://doi.org/10.1016/0304-3959(84)90167-2

25. Taddio, A., Nulman, I., Goldbach, M., Ipp, M. \& Koren, G. (1994). Use of lidocaine-prilocaine cream for vaccination pain in infants. The Journal of Pediatrics. 124(4), 643-648.

DOI: https://doi.org/10.1016/S0022-3476(05)83150-6

26. Taddio, A., Nulman, I., Koren, B.S., Stevens, B. \& Koren, G. (1995). A Revised Measure of Acute Pain in Infants. Journal of Pain and Symptom Management. 10, 456-463. DOI: https://doi.org/10.1016/08853924(95)00058-7

27. Brondani, J.T., Luna, S.P.L. \& Padovani, C.R. (2011). Refinement and initial validation of a multidimensional composite scale for use in assessing acute postoperative pain in cats. American Journal of Veterinary Research. 72(2), 174-183. DOI: https://doi.org/10.2460/ajvr.72.2.174

28. Holden, E., Calvo, G., Collins, M., Bell, A., Reid, J., Scott, E. M. \& Nolan, A. M. (2014). Evaluation of facial expression in acute pain in cats. Journal of Small Animal Practice. 55(12), 615-621. DOI: https://doi.org/10.1111/isap.12283

29. Calvo, G., Holden, E., Reid, J., Scott, E. M., Firth, A., Bell, A., Robertson, S. \& Nolan, A. M. (2014).Development of a behaviour-based measurement tool with defined intervention level for assessing acute pain in cats. Journal of Small Animal Practice. 55(12), 622-629.

DOI: https://doi.org/10.1111/isap.12280 
30. Hammond, F., Malec, J., Nick, T.D. \& Buschbacher, R. (2014). Sources of Error: Selection Bias, Information Bias, and Confounding. In. Handbook for Clinical Research : Design, Statistics, and Implementation. Demos Medical Publishing, New York, United States.

DOI: https://doi.org/10.1080/21646821.2016.1202719

31. Hammond, F., Malec, J., Nick, T.D. \& Buschbacher, R. (2014). Subject as Own Control. In. Handbook for Clinical Research : Design, Statistics, and Implementation Demos Medical Publishing, New York, United States. DOI: https://doi.org/10.1080/21646821.2016.1202719

32. Carney, H. C., Little, S., Brownlee-Tomasso, D., Harvey, A. M., Mattox, E., Robertson, S., Rucinsky, R. \& Manley, D. S. (2012). AAFP and ISFM Feline-Friendly Nursing Care Guidelines. Journal of Feline Medicine and Surgery. 14(5), 337-349. DOI: https://doi.org/10.1177/1098612X12445002

33. Kletsas, T. (2009). Low Stress Handling, Restraint and Behavior Modification of Dogs and Cats: Techniques for Patients Who Love Their Visits. Australian Veterinary Jounral. 90(6), 224.

DOI: https://doi.org/10.1111/j.1751-0813.2012.00943.x

34. Frank, D. (2014). Recognizing Behavioral Signs of Pain and Disease: A Guide for Practitioners. The Veterinary Clinics of North America: Small Animal Practice. 44(3), 507-524.

DOI: https://doi.org/10.1016/j.cvsm.2014.01.002

35. Robertson, S.A. (2008). Managing Pain in Feline Patients. Veterinary Clinics of North America: Small Animal Practice. 38(6), 1267-1290. DOI: https://doi.org/10.1016/i.cvsm.2008.06.008

36. Hammond, F., Malec, J., Nick, T.G. \& Buschbacher, R.(2016). Special Issues in Randomized Controlled Trials. In: Handbook for Clinical Research: Design, Statistics, and Implementation.New York: Demos Medical Publishing. DOI: https://doi.org/10.1080/21646821.2016.1202719

37. Hammond, F., Malec, J., Nick, T.G. \& Buschbacher, R. (2014). Sample Size and Power. In. Handbook for Clinical Research: Design, Statistics, and Implementation. New York: Demos Medical Publishing. DOI: https://doi.org/10.1080/21646821.2016.1202719

38. Zhang, Y., Hedo, R., Rivera, A., Rull, R., Richardson, S. \& Tu, X. M. (2019). Post hoc power analysis: is it an informative and meaningful analysis? General Psychiatry. 32(4).

DOI: https://doi.org/10.1136/gpsych-2019-100069

39. Riviere, J.E. \& Papich, M.G. (2001). Potential and problems of developing transdermal patches for veterinary applications. Advanced Drug Delivery Reviews. 50(3), 175-203.

DOI: https://doi.org/10.1016/S0169-409X(01)00157-0

40. Benson, H.A.E. (2012). Skin Structure, Function, and Permeation. Topical and Transdermal Drug Delivery: Principles and Practice. 1-22. DOI: https://doi.org/10.1002/9781118140505.ch1

41. Affolter, V.K. \& Moore, P.F. (1994). Histologie features of normal canine and feline skin. Clinics in Dermatology. 12(4), 491-497. DOI: https://doi.org/10.1016/0738-081X(94)90215-1

42. Benson, H.A.E. \& Watkinson, A.C. (2012). Transdermal and topical drug delivery principles and practice. Hoboken, N.J: Wiley.

43. Marks, S.L. (2003). Where Are We With Transdermal Drug Administration? Waltham Feline Medicine Symposium, [online]. Available

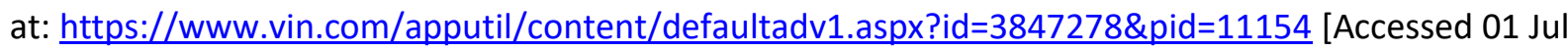
21]

44. Johnson, G.K., Squier, C.A., Johnson, W.T. \& Todd, G.L. (1987). Blood flow and epithelial thickness in different regions of feline oral mucosa and skin. Journal of Oral Pathology \& Medicine. 16(6), 317-321. DOI: https://doi.org/10.1111/j.1600-0714.1987.tb00701.x

45. Papich, M.G. (2016). Saunders Handbook of Veterinary Drugs: Small and Large Animal. Fourth ed., St. Louis, Mo: Elsevier.

46. Chadwick, S.H. (1985). Toxicity and Resuscitation in Lidocaineor Bupivacaine-infused Cats. Anesthesiology. 63(4), 385-390. DOI: https://doi.org/10.1097/00000542-198510000-00007

47. Fransson, B.A., Peck, K.E., Smith, J.K., Anthony, J.A. \& Mealey, K.L. (2002). Transdermal absorption of a liposome-encapsulated formulation of lidocaine following topical administration in cats. American Journal of Veterinary Research. 63(9), 1309-1312. DOI: https://doi.org/10.2460/ajvr.2002.63.1309 
48. Ko, J.C., Maxwell, L.K., Abbo, L.A. \& Weil, A.B. (2008). Pharmacokinetics of lidocaine following the application of $5 \%$ lidocaine patches to cats. Journal of Veterinary Pharmacology and Therapeutics. 31(4), 359-367. DOI: https://doi.org/10.1111/j.1365-2885.2008.00967.x

49. Weil, A.B., Ko, J. \& Inoue, T. (2007). The use of lidocaine patches. Compendium on Continuing Education for the Practicing Veterinarian. 29(4), 208-210.

50. Lener. E.V., Bucalo, B.D., Kist, D.A. \& Moy, R.L. (1997). Topical Anesthetic Agents in Dermatologic Surgery A Review. Dermatologic Surgery. 23(8), 673-683. DOI: https://doi.org/10.1111/i.15244725.1997.tb00388.x

51. Gammaitoni, R.A., Alvarez, A.N. \& Galer, S.B. (2003). Safety and Tolerability of the Lidocaine Patch 5\%, a Targeted Peripheral Analgesic: A Review of the Literature. The Journal of Clinical Pharmacology. 43(2), 111-117. DOI: https://doi.org/10.1177/0091270002239817

52. Mathews, K.A. (2008). Pain Management for the Pregnant, Lactating, and Neonatal to Pediatric Cat and Dog. The Veterinary Clinics of North America: Small Animal Practice. 38(6), 1291-1308.

DOI: https://doi.org/10.1016/j.cvsm.2008.07.001 


\section{EVIIDEFeE

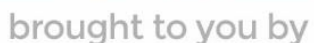 \\ RCVS KNOWLEDGE}

\section{Intellectual Property Rights}

Authors of Knowledge Summaries submitted to RCVS Knowledge for publication will retain copyright in their work, and will be required to grant RCVS Knowledge a non-exclusive license of the rights of copyright in the materials including but not limited to the right to publish, re-

publish, transmit, sell, distribute and otherwise use the materials in all languages and all media throughout the world, and to license or permit others to do so.

\section{Disclaimer}

Knowledge Summaries are a peer-reviewed article type which aims to answer a clinical question based on the best available current evidence. It does not override the responsibility

of the practitioner. Informed decisions should be made by considering such factors as individual clinical expertise and judgement along with patient's circumstances and owners' values. Knowledge Summaries are a resource to help inform and any opinions expressed within the Knowledge Summaries are the author's own and do not necessarily reflect the view of the RCVS Knowledge. Authors are responsible for the accuracy of the content. While the

Editor and Publisher believe that all content herein are in accord with current recommendations and practice at the time of publication, they accept no legal responsibility

for any errors or omissions, and make no warranty, express or implied, with respect to material contained within.

For further information please refer to our Terms of Use.

RCVS Knowledge is the independent charity associated with the Royal College of Veterinary Surgeons (RCVS). Our ambition is to become a global intermediary for evidence based veterinary knowledge by providing access to information

that is of immediate value to practicing veterinary professionals and directly contributes to evidence based clinical decision-making.

\section{https://www.veterinaryevidence.org/}

RCVS Knowledge is a registered Charity No. 230886.

Registered as a Company limited by guarantee in England and Wales No. 598443.

Registered Office: Belgravia House, 62-64 Horseferry Road, London SW1P 2AF

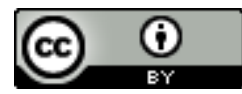

This work is licensed under a Creative Commons Attribution 4.0 International License 